\title{
Şekerpancarının Bazı Agroteknik Özelliklerinin Belirlenmesinde Kullanılabilecek Bir Sensör Geliştirilmesi
}

Ahmet ÇOLAK'
Ali lhsan ACAR

Geliş Tarihi: 23.05.2001

Özet: Bu çalıșmada, șekerpancarı hasadı öncesinde pancar sirasina ait bazı verileri elde edebilecek bir sensör geliștirmesi amaçlanmıştır. Bunu gerçekleştirmek için, toprak kanalında yapay bir pancar sırası oluşturulmuştur. Geliştirilen ahşap sensör ile dūşūk hızda ölçümler yapilmış, indâktif bir yol ölçerle elde edilen veriler bir data ișleme sistemi yardımıyla bilgisayara kaydedilmiştir. Microsoft Excel dosyası olarak saklanan verilerin zamana bağlı olarak elde edilen grafik görüntüleri, pancar sırasının profilini oluşturmada kullanılmıştır.

Anahtar Kelimeler: Şekerpancarı hasadı, sensör, agroteknik özellikjer

\section{Developing a Sensor to Determine the Some Agrotechnical Properties of Sugar Beet}

\begin{abstract}
The aim of this study, before sugar beet harvesting, was to develop a sensor for measuring the data were belonging to sugar beet row. For this purpose, a sugar beet row had been simulated on the soil canal. The measurements had been done at the low velocity by using developed wooden sensor. Then, data had been saved on the PC by using inductive sensor and data acquisition system. Graphical image which saved on the PC depend on time and ${ }^{*}$.xls file had given the profile of sugar beet row.
\end{abstract}

Key Words: Sugar beet harvesting, sensor, agrotechnical properties

\section{Giriş}

Şekerpancarı hasadında pancarın gerek iç, gerekse dış kalitesinin bozuimaması, istenen bir koşuldur. Bu nedenle hasat, agroteknik özelliklerle karşılıkıı uyum istemektedir (Brinkmann 1977). Sıra arası uzaklık, sıra úzeri uzaklık, pancar çapı, pancarın toprak üzerindeki yüksekliği gibi agroteknik özellikler, hasat makinasının fonksiyonel organları ile uyum içerisinde olmalıdır. Pancar hasadında dış kalitenin sağlanmasında önemli unsurların başında, ayar düzeni ölçülerinin pancar tarlasına uyumu geimektedir. Örneğin pancarlar arası sıra üzeri uzaklık;

- Ayar tamburunun çapı,

- Başkesme bıçağının biçim ve ölçüleri,

- Başkesme düzenin reaksiyon özelliği,

- Çalışma hızı

ile uyumlu olmalıdır. Ayar tamburu çapı ile en kăçak pancarlar arası sıra azeri uzaklık arasındaki ilișki Şekil 1 'de görülmektedir.

Şekil 1'deki geometrik ilişkilerden yararlanilarak pancarlar arasında olması gereken en küçük sıra üzeri uzaklık;

$$
L_{R_{\text {min }}} \geq \overline{A B}+n_{M}+\frac{d_{1}^{\prime}-\left(d_{1}+d_{2}\right)}{2}
$$

eşitliği ile verilebilmektedir (Wormanns 1976). Şekilde ve eşitlik [1]'de;

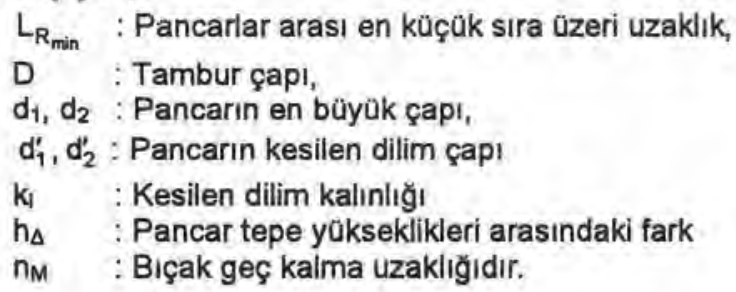

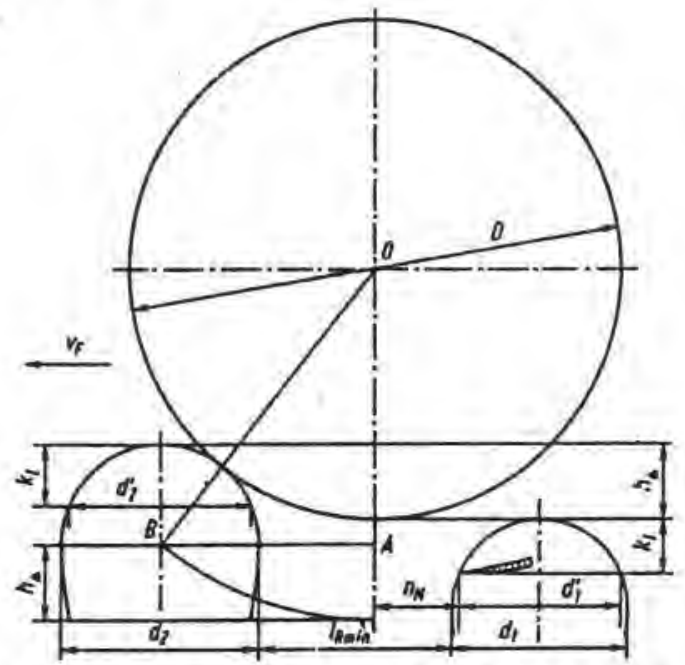

Şekil 1. Ayar tamburu çapı ile en küçăk pancarlar arasi sıra Qzeri uzaklığın ilişkisi (Wormanns 1976)

Şekildeki geometrik iliş̧ilerden gidilerek,

$\overline{A B}=\sqrt{(\overline{B O})^{2}-(\overline{A O})^{2}}=\sqrt{h_{\Delta}\left(D+d_{2}\right)-h_{\Delta}^{2}}$

ve sonuç olarak da:

$$
L_{R_{\min }} \geq \sqrt{h_{\Delta}\left(D+d_{2}\right)-h_{\Delta}^{2}}+n_{M}+\frac{d_{1}^{\prime}-\left(d_{1}+d_{2}\right)}{2}
$$

bağıntısı elde edilebilmektedir. Tambur çapının optimum değerler olarak $450 . .650 \mathrm{~mm}$ arasında olması öngörälmektedir. Şekerpancarının ônemli agroteknik özelliklerinden olan topraktan çıkma yăksekliği $(H)$ ile toprak seviyesindeki çapı (Ds) arasında;

$\mathrm{H}=0.702^{*} \mathrm{D}_{\mathrm{s}}$

ilişkisi bulunmaktadır (O'Dogherty 1986).

\footnotetext{
${ }^{1}$ Ankara Oniv. Ziraat Fak. Tarım Makinaları Bölümü-Ankara
} 
Başkesme bıçă̌ının yeri ise tarladaki pancar çaplarına ve pancarların topraktan çikma yükseklikleri ile en alt yeşil yaprak gozlerine bağlı olmaktadır. Bıçak tambur doşey ekseninden, pancarın kesildigi yerdeki yarıçapi kadar geride (geç kalma uzaklığt) ve kesilecek dilim kalınlığı kadar aşağıda bulunmalıdır (Albrecht 1961).

Şekerpancarı sıra uzeri uzaklıklarına gore bas kesme dazenlerinin uygun ayar sınirlarinin belirtenmesi onemii bir ayrintı olmaktadir (Olbrich and Jakob 1987). Uygulamada pancar hasat makinalarında başkesme bıçac̆ının yeri ayarlanabllir yapilmaktadır. Ancak bu ayarlartialarin olabildiğince doğru bir şekilde yapılabilmesi için tarla ile ilgili bazı bilgilerin bilinmesinde yarar olacağı duşancesindeyiz. Çalışma bu amaca younelik olarak gerçekleştirilmiştir

\section{Materyal ve Yöntem}

Denemeler, Ankara Universitesi Ziraat Fakoltesi Tarım Makinaları Bolúmo Toprak Işleme Aletleri Laboratuvarındaki toprak kanalında gerçekleştirilmiștir

Tarladan yaprakłarı kesilerék getirilmiş olan farkı bôyäklük ve çaptaki pancarlar değişik sıra ozeri uzaklıklarında toprak kanalı içerisinde sabitienmişlerdir. Böylece pancarların dcğal yetişme ortamlarındaki konumlanının benzetiminin yapıldığı bir pancar sırası olușturulmuștur.

Toprak kanalı ozerindeki ray (R) sistemlerinde çalışan toprak kanali arabasinın (TKA) şasisine (Ş) mafsallı olarak bağlanmış bir çatıya (C) sahip olan ahşaptan yapilmiş sensobr (S) çatiya civatalarla bağli bir mil (M) Qzerine iki uçtan rulmanlarla yataklandirımıştır. Böylece mil azerinde serbestçe dönebilmektedir. Bu yapi, sensore pancar uzerine rahatça tımanabilme yeteneği kazandirmıştır. Sensơrün yukarı aşağı hareketinin algilanarak eloktriksel boyoklaklere donoştaralmesinde indoktif bir yol ölçer (YO) kullanilmıştır.

Indaktif yol öly̧erin hareketli çubuğu (HC) alt ucundan sensörün çatısına, sensör milinin ekseni hizasına gelecek ve milin yörüngesine paralel olarak hareket edebilecek serbestlikte bağlanmiştir. Yol ollcerin ana govdesi ise sabit bir yükseklikte ancak sensör yourüngesine uyum sağlayabilecek serbestlikte özel bir bağlantı elemanina (OBE) yataklandırılmıştır. Algılayıcı sistemin şematlk göronulşu Şekil 2'de verilmiştir.

Yol olçer ozel bir ara kablosu (AK) ile yükselticiye bağlanmıştır. Yukseltici çıkışı ise PCL-818HG kartına sahip bir veri işleme (data acquisition) sistemi yardımıyla PC bilgisayara aktarıımıştır. Boylelikle fiziksel olarak algılanan veriler once analog elektriksel böyakloklere, ardindan da bilgisayara aktarilabilecek tanımlanmıs sayısal (digital) boyokjoklere dónusştaralmüştar. Şekil 3'de şematik görünuşú verilen data toplarna ve ișleme sisteminde yazılım olarak GENIE 3.00 kullanılmıştır.

Öncelikje sensörön çeşitli yüksekliklerindeki verilerin olçamleri yapılarak, yakseklikler ve bilgisayarda kaydedilen datalarin kalibrasyan degerleri elde edilmiştir. Bu amaçla $2 \mathrm{~cm}$ kalınlığında ahşap bloklar kullanılmıştır. Kalibrasyon işlemi sonucunda sensörden elde edilen yakseklikler lle kaydedilen veriler arasında doğrusal bir
Ilișki saptanmıștır. Yazılımın olçeklendirme (scaling) seçeneği yardımıyla algılanan ve kaydedilen değerlerín denkliği sağlanarak ulçam sistemi kalibre edilmiştir.

Kalibrasyon ve ólçeklendirme işlemleri sonrasında sensör, toprak kanalı arabasıyla en daşok değer olan $0.39 \mathrm{~m} / \mathrm{s}$ hizla çekilmiştir. Toprak kanalına kille sıkıștırılarak sabitlenen pancarlar üzerinden alınan veriler bilgisayarda Microsoft Excel dosyası olarak kaydedilmiştir. Sensördeki sürekli algılama transducer (indoktif yol olçer) tarafindan yine kesintisiz olarak yokselticiye (amplifier) iletilmiş, ancak PCL-818HG, GENIE 3.00 tarafindan 25 ms'de 1 veri kaydedecek şekilde programlanmıştır.

Toprak kanalında bulunan pancar sırasındaki pancarlar ise numaralanarak;

- Toprak seviyesindeki çap,

- Topraktan cikma yoksekliği,

- Pancarların serbest sıra uzeri uzaklığı (LRmin)

değerleri de șerit metre ve kumpas kullanilarak ölçulinüş ve elle kaydedilmiștir.

Elle ölçolen ve gefiştirilen sensör kullanilarak bilgisayara kaydedilen verilerin, grup içi korelasyon katsayıları belirlenmiş ve degerler grafiksel olarak ifade edilmiştir.

\section{Bulgular ve Tartişma}

Bilgisayara Excel dosyası olarak kaydedilmiş olan verilerin zamana bağlı grafikleri çizdirilerek, pancarların yüksekllk ve serbest sıra Uzeri uzaklık değerleri elde edilmiștir. Şekil 4 'de ise dort pancara llişkin kaydedllen verilerin zamana gobre değișimiyle elde edilen grafik görülmektedir.

Şekil 4 incelendiğinde, dôşey eksende pancar yaksekliğinin doğrudan okunduğu görölebilmektedir. Yatay eksen ise saniyede kaydedilen data sayısını göstermekte olup, sensoran ilerleme hızı dikkate alınarak birim uzuniuk değerlerine dönüşturalebilmektedir.

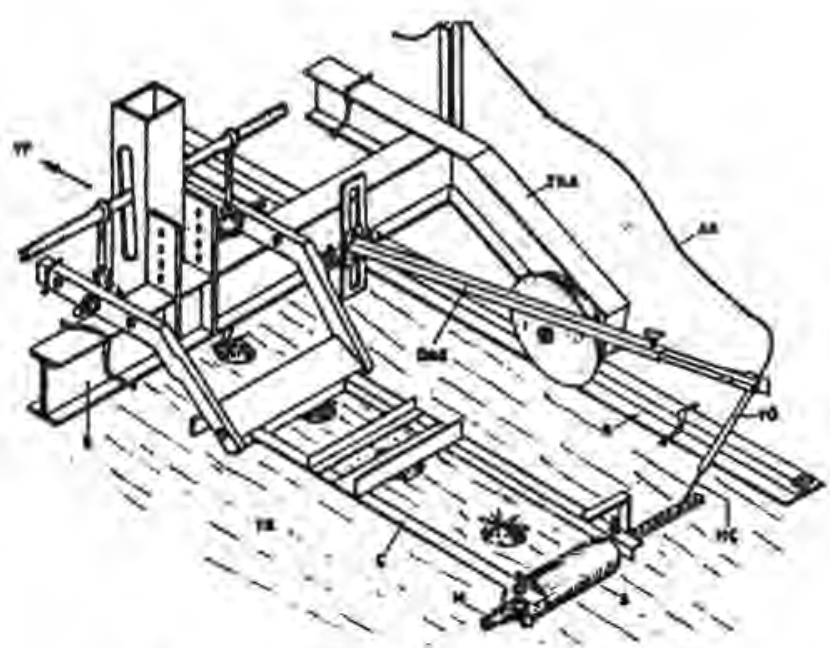

Şckil 2. Algulayıcı sistemin șematik gèrunușo 


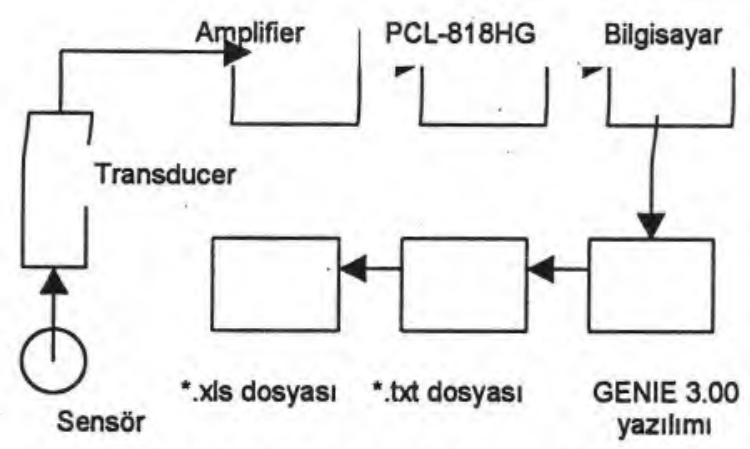

Şekil 3. Data toplama ve işleme sistemi
Bilgisayarda grafiksel olarak tarla profilini gösteren veriler elle ölçülen değerlerle karşılaştırılmıştır. Pancarların topraktan yükseklikleri ile ilgili olarak, bilgisayardan alınan değerler ile elle ölçülen kontrol değerlerinin dağılımı Şekil 5'de verilmiştir. Yapılan istatistik analiz sonucunda grup içi korelasyon katsayısı $0.96{ }^{*}$ $(p<0.01)$ olarak saptanmıştır. Benzer biçimde pancarlararası serbest uzaklıklarla ilgili olarak, bilgisayardan alınan değerler ile elle ölçülen kontrol değerleri de Şekil 6'da görülmektedir. Bu değerler istatistiksel olarak analiz edilmiş. ve sonuçta, grup içi korelasyon katsayısı değeri $0.89^{\circ *}(p<0.01)$ olarak tespit edilmiştir.

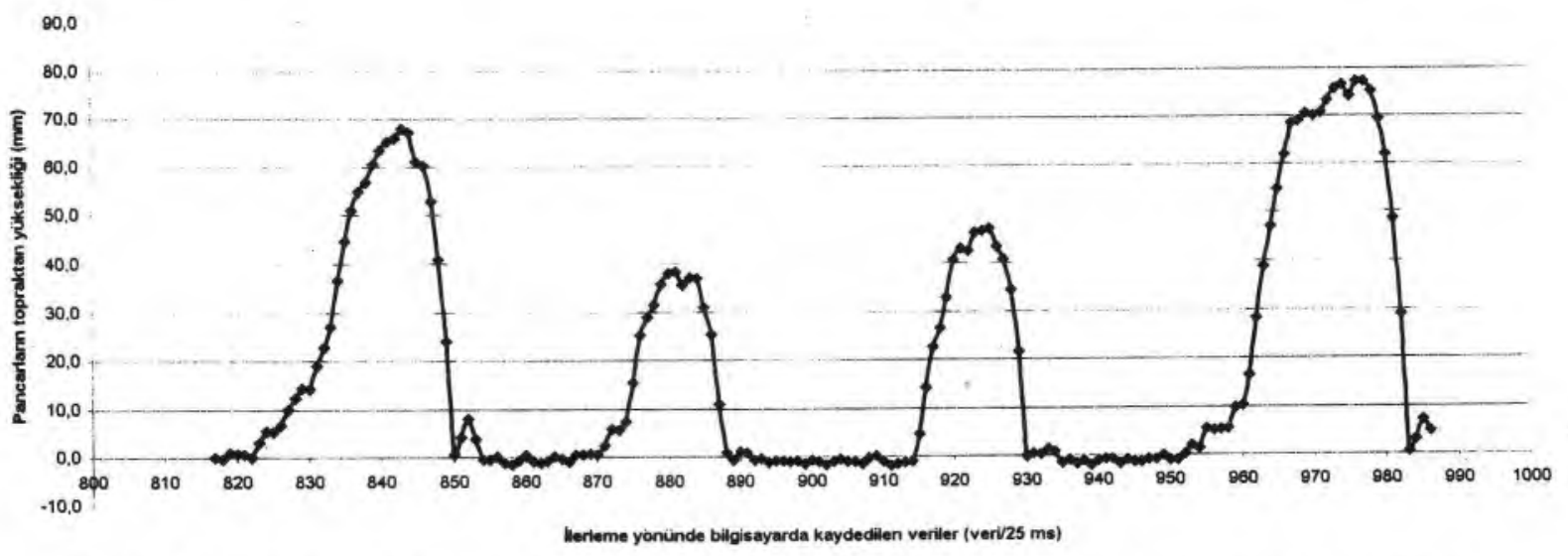

Şekil 4. Pancar sırasındaki rastgele seçilen ardışık dört pancara ilişkin kaydedilen verilerin zamana göre değişimi

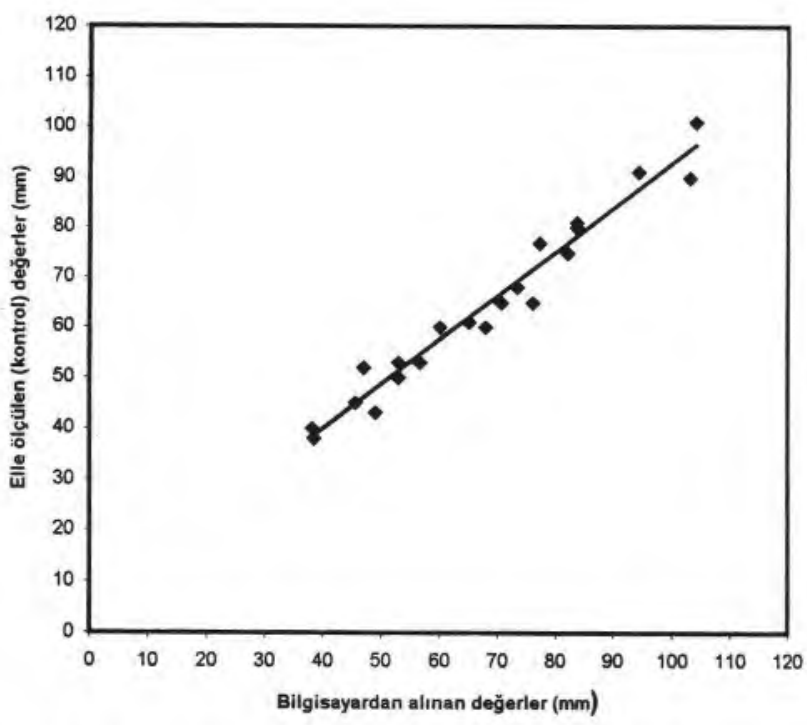

Şekil 5. Pancariarın topraktan yükseklikleri ile ilgili olarak, bilgisayardan alınan değerlerin ve elle ölçülen kontro değerlerinin dağılımı

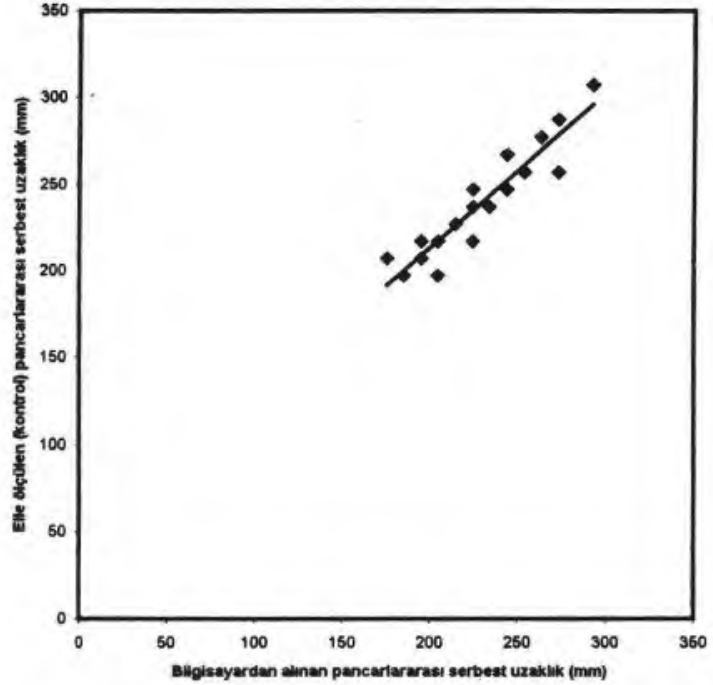

Şekil 6. Pancarların serbest sıra üzeri uzaklıkları ile ilgili olarak, bilgisayardan alınan değerlerin ve elle ölçălen kontrol değerlerinin dağııımı 


\section{Sonuç}

Bu çalışmada geliştirilen sensörle algılanan veriler ve elle yapılan ölçümler arasında istatistiksel anlamda önemli bir fark görülmemiştir. Sensörle algılanan veriler kullanılarak, tarladaki pancarların yükseklikleri 0.96" $(p<0.01)$ oranında, pancarlararası serbest uzaklıklar da $0.89^{\circ}(p<0.01)$ oranında tahmin edilebilecektir. Bu nedenle, geliştirilen sensörün kısa sürede, bir tarlayı karakterize edebilecek sayıdaki pancar sırasının profilini çıkarabilecek özellikte olduğu kanısına varılmıştır. Böylece, pancar hasat makinası baş kesme düzeni ayarlarının daha doğru yapılabilmesi olanaklı olacaktır. Bu durum, hasattaki baş kesme kayıplarının azaltımasını ve baş kesme kalitesinin iyileştirilmesini sağlayacaktır. Ayrıca sensör, şeker pancarı hasat makinalarına ilişkin bazı tasarım parametrelerinin belirlenmesine esas oluşturacak kinematik büyüklüklerin elde edilmesinde de kullanılabilecektir.

\section{Kaynaklar}

Albrecht, E. H. 1961. Beitrag zur Konstruktiven Auslegung von Rübenköpfelementen. Grundlagen der Landtechnik 13: 54 59, Bonn.

Brinkmann, W. 1977. Moderne anbau-und erntetechniken im zuckerrubenbau erforderngegenseitige Anpassung. Landtechnik 9: 360-366, Bonn.

O'Dogherty, M. J. 1986. The design of feeler wheel toppers for sugar beet 2 . specification of topper mass and spring and damper restraint. Journal of Agricultural Engineering Research, 34: 319-332.

Olbrich, A. und P. Jakob, 1987. Maschineneneinstellung und verbesserung der köpfqualität der zuckerrübenköpflader 6ORCS/SC 1-03 und SC 1-04. Agrartechnik 10: 442-445, Berlin.

Wormanns, G. 1976. Zusammenhänge zwischen standraumzumessung und köpfqualität bei zuckerrüben. Agrartechnik 4: 179-181, Berlin.

Yurtsever, N. 1984. Deneysel Istatistik Metodları. T.C. Tarım Orman ve Köyişleri Bakanlığı Köy Hizmetleri Genel Müdürlüğü Yayınları: 121, Ankara. 